\title{
Nur Balkan Atlı (1953-2019)
}

İstanbul Üniversitesi, Edebiyat Fakültesi, Arkeoloji Bölümü, Tarih Öncesi Arkeolojisi Anabilim Dalı öğretim üyesi Prof. Dr. Nur Balkan Atlı, 10 Nisan 2019'da, 66 yaşında aramızdan ayrıldı. Henüz emekli olmamıştı, Anabilim Dalı başkanlığı görevini sürdürmekteydi; en aktif ve en verimli olabilecek bu genç yaşında kendisini kaybettik. Ailesini, dostlarını, yetiştirdiği öğrencileri büyük bir şaşkınlık ve üzüntü içinde bırakan kaybından bu yana her geçen gün, bilimsel duruşu, bilimsel etik anlayışı, arkadaşlı̆ğ ve dostluğu ile kendisini çok daha fazla arıyoruz.

Nur Balkan Atl1, İstanbul Üniversitesi Arkeoloji ve Sanat Tarihi Bölümü'nde, 1970lerin başında başladığı akademik eğitimine sağlık sorunları nedeniyle ara vermiş, ardından Fransa'ya giderek Paris’te, Paris I- Sorbonne Üniversitesi'nde eğitimini tamamlamış, Prof. Dr. Ufuk Esin'in Anabilim Dalı başkanı olduğu dönemde, 1987 yılında, Prehistorya Anabilim Dalı'nda uzman olarak çalışmaya başlamıştı. Kendisini kaybettiğimiz 2019 yılına kadar lisans ve lisans üstü dersleri verdi, lisans üstü tezleri yönetti, eğitimin yanısıra araştırmacı yönü ile çeşitli arazi çalışmaları yürüttü.

Aydın'da 1953 yılının 2 Ocak günü doğan Nur Balkan, arkeolog olmayı çocuk yaşlarında aklına koymuştu. Robert College'den mezun olduktan sonra, çok sevdiği erkek kardeşi Ali Balkan'dan edindiğimiz bilgiye göre, girdiği üniversite giriş sınavında üstün bir başarı elde etmiş, aldığı puan ile sıralamada, ilk sıralarda yer alması ve en yüksek puanlı bölümlere girebilecek olmasına rağmen, ısrarla arkeolojiyi seçmişti. İstanbul Üniversitesi'ndeki ilk eğitim yılında geçirdiği yüz felci nedeniyle eğitimine ara vermek zorunda kalmış, ancak bu süreçte gittiği Paris’te, Paris I- Sorbonne Üniversitesi Antropoloji-Etnoloji-Prehistorya bölümüne kayıt yaptırarak, Prof. Dr. J. L. Huot ve Prof. Dr. J. Cauvin’in öğrencisi olmuştu. Mükemmel İngilizcesinin yanı sıra Fransızca dilini de kısa sürede öğrenerek önce Lisans eğitimini, arkadan Yüksek Lisans eğitimini tamamlamış, sonrasında Anadolu'nun Neolitikleşmesi konulu doktora tezini yazmıştı. Doktorasını 1985 yılında trés honorable avec félicitations du jury derecesi/ibaresi ile almıştı.

Öğrenciliği sırasında, hocası olmasının yanı sıra tez danışmanı da olan Jacques Cauvin ile çok sevgili dostu, arkadaşı, meslektaşı Marie-Claire Cauvin ile birlikte Malatya'da baraj altında kalacak yerleşmeleri kurtarma kazıları kapsamında Cafer Höyük kazılarına katılmıştı. Arazi ve atölye çalışmalarının yanı sıra tüm kazı ve araştırma projelerinde Cauvin'lerin en büyük yardımcıları Nur Balkan idi. Çevirmen, idari ve mali işlerin yürütücüsü olarak her 
türlü sorumluluk onda idi; nitekim, Cafer Höyük gibi, yaklaşık aynı yıllarda Suriye'de El Kown ve Qdeir kazılarına katılmış, genç yaşına rağmen sorumluluk anlayışı, organizasyon becerisi ve kararlı duruşu ile bu güç görevlerin altından kalkmayı bilmişti.

Doktora eğitimi ve arazi çalışmalarında, bugün her biri kendi alanında uzmanlaşmış akademisyenlerden Barcelona Otonom Üniversitesi, Prehistorya Bölümü öğretim üyelerinden Prof. Dr. Miquel Molist ve Girit Üniversitesi Tarih ve Arkeoloji Bölümü’nde Prehistorya Bölümü profesörü Prof. Dr. Katerina Kopaka gibi bilim insanlarıyla çalışmıştı. Doktora eğitimini tamamladıktan sonra yurda dönerek, İstanbul Üniversitesi Prehistorya Anabilim Dalı'na, uzman kadrosu ile girdi. Aynı yıl, Prof. Ufuk Esin'in Malatya'da yürütmekte olduğu Değirmentepe kazılarının son yılıydı. Nur Balkan, öğrencilik yıllarında katıldığı Malatya Cafer Höyük kazıları nedeniyle çok iyi bildiği bölgede, Malatya' da, bu kez Değirmentepe çalışmalarına katıldı. Analiz edilmeyi bekleyen onbinlerce yontma taş alet üzerindeki çalışmaları ile Ufuk Esin'le uzun yıllar sürecek ortak projelere başlamış oldu. Nitekim Değirmentepe'nin su altında kalmasından bir yıl sonra, 1989 yılında, yine Ufuk Esin başkanlığında başlayan bu kez Orta Anadolu Bölgesi'ndeki Aşıklı Höyük araştırmalarına katıldı. İlk yıllarda yontma taş uzmanı, daha sonrasında başkan yardımcısı ve son olarak da 2001-2005 yılları arasında Aşıklı Höyük projesinin başkanı olarak görev aldı.

Aşıklı Höyük obsidiyen alet yapımı çalışmalarını yürüttüğü 19901 yıllarda, ilk gözlemler ve ön sonuçlar bağlamında yeni ortaya çıkan araştırma soruları ve varsayımların, mevcut çalışma metodolojisi ile çözümlenemeyeceğini düşünen ve yeni arayışlara giren Nur Hoca, incelemelerine mutlak şekilde teknoloji, kullanım izi analizleri, deneysel arkeoloji gibi o dönem için yenilikçi yöntemlerin katılmasını ön gördü. Doktorasını yaptığı ve birlikte çalıştığ 1 Fransa'daki hocaları ve meslektaşlarını bu amaçla Aşıklı Höyük'e davet ederek bir yandan yeni sorularla yeni projeler oluşturdu, diğer yandan teknolojik analiz yöntemi ve yaklaşımı ile tarih öncesi taş işçiliği çalışmalarında yeni bir dönemin başlamasını sağladı. Marie Claire Cauvin, Didier Binder, Gerard Deaphrahamien ve Frederic Abbes ile başlayan bu işbirliği, sonraki yıllarda gelişerek ve başka projeleri de kapsayacak biçimde yayılarak sürdü. Catherine Kuzucuoğlu, Jacques Pelegrin, Laurence Astruc, Michele Grenet, Martin Godon, Ludovic Slimak ve Damase Moralis gibi bilim insanlarının gerek Kapadokya obsidiyen araştırmaları gerekse Orta Anadolu Bölgesi Neolitik yerleşmelerinde yeni, çokuluslu araştırmalar yürütmeleri, Nur Balkan'ın bilimsel anlayışının göstergeleridir. Kendisine borçlu olduğumuz, halen devam etmekte olan bu yakın işbirliği ve karşılıklı bilimsel alış verişin kuşkusuz en önemli kazanımlarından biri, yürütülen bu ortak projeler kapsamında yontma taş iş̧̧iliğinin yeni uzmanlık dallarında öğrenci yetiştirilmesi idi. Bugün, yontma taş alet teknolojisi, tipolojisi, kaynak analizleri, kullanım izi analizleri gibi konularda yetiştirmiş olduğu çok sayıdaki öğrencilerinden üçü, İstanbul Üniversitesi Tarih Öncesi Arkeolojisi Anabilim Dalı’nda, doçent derecesine sahip, uluslar arası düzeyde saygın üç bilim kadınıdır. 
Nur Balkan, Aşıklı Höyük yontma taş alet işçiliği çalışmalarına devam ederken, Aşıklı’nın içinde bulunduğu Kapadokya Bölgesi'nde bulunan obsidiyen kaynaklarının kullanımı, tarih öncesi çağları boyunca obsidiyenin bölgeler ve tarih öncesi topluluklar arasında etkileşimi sağlayan malzeme olması, yeni verilerle Orta Anadolu'dan Doğu Akdeniz kıyıları ve Orta Fırat bölgesine kadar uzanan bir obsidiyen alışveriş ağının yeni özellikleri gibi sorular, hocayı ve meslektaşlarını Kapadokya obsidiyen yataklarında bir araştırma projesi başlatmaya yöneltti. 1995 yılında Aksaray, Nevşehir, Niğde İlleri Obsidiyen Araştırmaları Projesi adıyla yüzey araştırmalarına başladı. Marie Claire Cauvin ile birlikte yürüttüğü bu araştırmada pek çok buluntu yerinin yanı sıra iki yıl sonra kazısına başlayacağı Kömürcü-Kaletepe Neolitik obsidiyen işliğini saptad1. Göllüdağ’ın Kömürcü köyüne bakan yamaçlarında 1997 y1lında, o dönem Centre National de la Recherche Scientifique - CNRS' in araştırma başkanı olan Didier Binder ile birlikte Kömürcü-Kaletepe Obsidiyen Atölyesi kazısına başladı. 2001 yılına kadar devam eden kazılarda elde edilen sonuçlar, yeni varsayımların ortaya atılmasını, o güne kadar ağırlıklı olarak geleneksel yollarla yapılan Neolitik yaşam biçimi açıklamalarına ve kültür bölgeleri karşılaştırmalarına farklı bakış açıları sağladı, yorumlamaları zenginleştirdi. Nitekim, önermeleri, proje uzmanlarının bölgede yeni obsidiyen kaynak analizleri, yeni teknolojik ve tipolojik araştırmalara başlamalarına neden oldu, çevresel ve iklimsel sorunların tekrardan ele alınmasını gerektirdi.

Kömürcü-Kaletepe işlik kazıları sırasında ekibin yaptığı çevre araştırmaları, Türkiye'nin sayılı Alt Paleolitik buluntu yerlerinden biri olarak karşımıza çıkacak, Kaletepe Deresi 3 adlı buluntu yerinin saptanmasına da neden oldu. Kaletepe Deresi 3, bölgede daha önceden bilinmeyen bir dönemi işaret etmekteydi. Kazı çalışmalarının başlayabilmesi için Nur hoca, kendi uzmanlık alanı dışında kaldığı için, Paleolitik çağ uzmanlarından meslektaşları Ludovic Slimak ve Steven Kuhn'u davet etti. 2001 yılında (2001-2006, 2008) kazı çalışmaları başladı. Kazı sonuçları, Orta Anadolu'nun Niğde ilinde, Göllüdağ sınırları içerisinde, arkeolojik kazılarla araştırılmış, stratigrafisi belirlenmiş ve mutlak tarihlemesi yapılmış Anadolu'nun en eski Paleolitik buluntu yerlerinden birinin varlığını ortaya koydu.

Gerek Kömürcü-Kaletepe Neolitik işlik kazısı, gerek Kaletepe Deresi 3 Paleolitik kazısı sırasındaki çevresel gözlemler ve çok disiplinli araştırmalar, Göllüdağ' da o zamana kadar saptanmış olan buluntu yerlerinden çok daha fazlasının var olduğunu göstermekteydi. Bölgedeki ciddi erozyon nedeniyle yeni ortaya çıkan buluntu yerleri, tarih öncesinin farklı dönemlerine özgü işlikler, Göllüdağ' daki araştırmaların devam etme gerekliliğini ortaya koydu, projenin kapsamını genişletti. 2007 yılında dört yıl sürecek olan ve Göllüdağ’’n tümünün taranmasını hedefleyen proje, 2011 yılına kadar sürdü. Araştırmalar sonucu, obsidiyen kaynakları, vadilerde farklı akıntılar ve sayısız yongalama işleminden kalan ürünler, artıklar saptand1.

Nur hocanın arazide yürüttüğü bu proje, Göllüdağ ve çevresindeki son proje idi, ancak Kömürcü-Kaletepe obsidiyen işliği kazısı ile bu son Göllüdağ projesi arasına iki kazı projesi 
daha sığdırmıştı. Bunlardan biri Ufuk Esin hocanın sağlık sorunları nedeniyle Aşıklı Höyük kazı başkanlığını Nur hocaya devrettiği dört sezon, diğeri ise Karkamış baraj gölü suları tehdidi altındaki Akarçay Tepe kurtarma kazılarındaki 10 sezon idi. Aşıklı Höyük’te, Prof. Esin başkanlığındaki kazılarda, höyüğün MÖ 8.bin yıla tarihlenen geç dönem yerleşmesine odaklanılmıştı. Daha erken tabakaların kazısı 2000'li yıllarda başlamış ve sonradan MÖ 9.bin yılın ikinci yarısına tarihleneceği anlaşılacak olan yuvarlak/oval planlı toprağa yarı-gömük binalar kendini göstermeye başlamıştı. Nur hoca, başkanlığı devraldıktan sonra küçük bir ekip ile, alt tabakaların ortaya çıkarılmasını hedefleyen çalışmalara başkanlık etti. Kurtarma kazıları sırasında geniş alanlarda yürütülen kazılarla ortaya çıkarılan ve birikmeye başlayan malzemenin çalışılmasına öncelik vererek, lisans üstü düzeyde tezlerin yapılmasını sağladı.

1998 yılında, Aşıklı Höyük’te obsidiyen işçiliği çalışmalarını sürdürürken, Karkamış baraj gölü suları altında kalacak yerleşmeleri kurtarma projesi kapsamında, Şanlıurfa ilinin Birecik ilçesi sınırları içinde kalan Akarçay Tepe kazılarına başkanlık etmesi için bu satırların yazarı ve Aslı Erim Özdoğan tarafından kendisine götürülen teklifi isteksizce de olsa kabul etti. Neolitik Çağ'ın Çanak Çömleksiz Evresi'nin yanı sıra, Çanak Çömlekli Evre'ye geçiş ve Gelişkin Çanak Çömlekli Evre bulguları veren Akarçay Tepe'deki kurtarma kazılarında birlikte çalışmak üzere, Fransa'da birlikte doktora yapmış olduğu sevgili arkadaşı ve meslektaşı Miquel Molist ve ekibini Akarçay Tepe'ye davet etti. Fırat nehrinin yakınında, Akarçay köyünün hemen batısındaki Neolitik Akarçay Tepe'de araştırmaların çok-uluslu ve çok-disiplinli olarak, Barcelona Autonome Üniversitesi ve Tsukuba Üniversitesi uzmanlarının katılımıyla, on yıl kadar devam etmesini sağladı. Pek çok lisans öğrencisinin farklı alanlarda uzmanlaşması, yeni proje ve yayınların yapılması, hocanın kazı ve araştırma kadar önemsediği şeylerdi; bilimsel anlayışı paylaşım ve yeni kuşakları desteklemek ve yönlendirmekti.

Nur hocanın ilgi alanı ve araştırma konuları yalnızca Neolitik Çağ ve yontma taş alet işçiliği ile sınırlı değildi; Fransa' da aldığı eğitim sırasında kuramsal arkeolojinin, arkeolojik düşünce tarihinin arkeolojik eğitimde ve uygulamadaki vazgeçilmezliğini farkederek, Tarih Öncesi Arkeolojisi Anabilim Dalı'na girdiği ilk yıllarda kuramsal arkeolojiyi yeni bir ders olarak programa koydu. Yontma taş teknolojisi gibi teknik bir konunun kuramsal yaklaşımlarla örülerek çalışılmasının sonuçlarını, katıldığı her ulusal ya da uluslararası bildiride, yayınlarında, raporlarında görmek mümkündü. Düşünen, sorgulayan özelliği ile, yontma taş işçiliği alanındaki olmazsa olmaz tanımsal ve teknik araştırmaları günümüzle ve insanlıkla bağdaştırmayı bilmiş, bu işleri niçin yaptığımızı sorgulamış, çok sevdiği tarihçi Marc Bloch'un deyişiyle '...bir bilim er veya geç daha iyi yaşamamıza yardım etmeli...' anlayışını benimsemişti. Tarih öncesi çağlar, alet yapımı, etnoarkeoloji, genel prehistorya, Prof. Ufuk Esin'in emekliliği sonrasında üstlendiği prehistorik sanat gibi lisans ve lisans üstü derslerinin tümünü, öğrencilerin düşünmesi ve sorgulamasını sağlamak amacıyla kuramsal 
yaklaşımlarla besleyerek zenginleştirmişti. Prehistorya (Tarih Öncesi Arkeolojisi) Anabilim Dalı'nın kurulma sürecinde ağırlıklı olarak Alman ve Amerikan ekolünden etkilenmiş anlayışa, Nur hoca kuramsal ağırlıklı bir başka bakış açısı yolu kazandırmıştır. CNRS, Fransız Anadolu Araştırmaları/İstanbul gibi kurumlar ve burada görevli meslektaşlarımız ve akademisyenler ile işbirliği ve karşılıklı bilimsel alışveriş, proje ortaklıkları, toplantı, sempozyum organizasyonları, Nur hocanın hiçbir zaman kendisini ya da adını ön plana çıkartmadan meslektaşlarına, genç kuşaklara verdiği desteklerden yalnızca bir kaçıdır.

Kendisini ilk kez tanıdığım 1987 yılında, önce Değirmentepe, sonrasında sırasıyla Aşıklı Höyük, Musular, Akarçay Tepe Neolitik araştırma projelerinde çalıştık. KömürcüKaletepe Obsidiyen Atölyesi ve Kapadokya Obsidiyen Araştırmaları'na başladığı yıllarda aynı projede olmasak da aynı bölgede çalışıyor olmanın ayrıcalığını yaşadık; araştırma özelinde desteği ya da kişisel cesaretlendirmeleri hiç eksik olmadı. Fakültede, prehistorya koridorunun sonundaki 101 no.lu odada, Aslı Erim Özdoğan ile birlikte üçümüzün çalıştığ1 on yıllar boyunca günlük sohbetlerde, bilimsel tartışmalarda, arkeoloji dışı günlük hayatta, birlikte gittiğimiz yemekler, toplantılar, sempozyum, kongre ve tatillerde kendisiyle hemen her alanda, çiçek yetiştirmekten tarih öncesine, yemek pişirmekten eğitim sistemine varana kadar pek çok alanda pek çok şey konuştuk, tartıştık. Nur, derin ve çok yönlü tartışmaya açık, paylaşımcı, alçak gönüllü kişiliği ile gerçek bir bilim insanı idi. İlkeli duruşu, sakin, ağırbaşlı ve entellektüel kişiliği ile kendisini tanımış olmak, 30 yılı aşkın süreyle birlikte çalışmış ve üretmiş olmak, büyük ayrıcalık. Yetiştirdiği öğrencileri ve meslektaşları olarak onun düşüncelerini, bilimsel anlayış ve yaklaşımlarını yaşatma, sürdürme ve aktarma çabamız, kısmen üzüntümüzü hafifletmeye yarasa da kendisini bu kadar erken kaybetmiş olmanın acısını dindirmiyor.

\section{Mihriban Özbaşaran}

Tarih Öncesi Arkeolojisi Anabilim Dalı

Bloch, M. 1994, Tarihin Savunusu ya da Tarihçilik Mesleği, Gece Yayınları, Ankara 




Nur Balkan Hoca, Kapadokya Yüzey Araştırması sırasında



Kapadokya Yüzey Araştırmaları sırasında atölyede obsidiyen çizimi 